\title{
Amplatzer occluders for refractory esophago-respiratory fistulas: a case series
}

\section{(ㄷ)(1) $\ominus$}

Authors

Arthur Belle ${ }^{1}$, Christine Lorut ${ }^{2}$, Aurélie Lefebvre ${ }^{2}$, Einas Abou Ali ${ }^{1,4}$, Rachel Hallit ${ }^{1}$, Sarah Leblanc ${ }^{1,3}$, Benoit Bordacahar $^{1}$, Romain Coriat ${ }^{1,4}$, Nicolas Roche ${ }^{2,4}$, Stanislas Chaussade ${ }^{1,4}$, Maximilien Barret ${ }^{1,4}$

Institutions

1 Department of Gastroenterology and Digestive Oncology, Cochin Hospital, Assistance PubliqueHôpitaux de Paris, Paris, France

2 Departement of Respiratory Medicine, Cochin Hospital, Assistance Publique-Hôpitaux de Paris, Paris, France

3 Department of Hepato-Gastroenterology, Ramsay Private Hospital Jean-Mermoz, Lyon, France

4 University of Paris, Paris, France

submitted 12.1.2021

accepted after revision 29.3.2021

Bibliography

Endosc Int Open 2021; 09: E1350-E1354

DOI 10.1055/a-1490-9001

ISSN 2364-3722

(c) 2021. The Author(s).

This is an open access article published by Thieme under the terms of the Creative Commons Attribution-NonDerivative-NonCommercial License, permitting copying and reproduction so long as the original work is given appropriate credit. Contents may not be used for commercial purposes, or adapted, remixed, transformed or built upon. (https://creativecommons.org/licenses/by-nc-nd/4.0/)

Georg Thieme Verlag KG, Rüdigerstraße 14,

70469 Stuttgart, Germany

Corresponding author

Maximilien Barret, Department of Gastroenterology and

Digestive Oncology, Cochin Hospital, Assistance Publique-

Hôpitaux de Paris, 27 rue du Faubourg St Jacques, 75014,
Paris, France

Fax: +0033158413865

maximilien.barret@aphp.fr

\section{ABSTRACT}

Background and study aims Endoscopic management of esophagorespiratory fistulas (ERF) is challenging and currently available options (stents, double pigtail, endoscopic vacuum therapy) are not very effective. We report the feasibility and efficacy of endoscopic placement of Amplatzer cardiovascular occluders for this indication.

Patients and methods This was a single-center, prospective study (June 2019 to September 2020) of all patients with non-malignant ERF persistent after conventional management with esophageal and/or tracheal stents. The primary outcome was the technical feasibility of Amplatzer placement. Secondary outcomes were clinical success defined by effective ERF occlusion and resolution of respiratory symptoms allowing oral food intake.

Results Endoscopic placement of Amplatzer occluders was feasible in $83 \%$ of patients (5/6), with a $50 \%(3 / 6)$ clinical success rate at 9 months. The mortality rate was $33 \%$ (2/6). Conclusions An Amplatzer cardiac or vascular occluder is a feasible and safe treatment option for refractory ERF, with a $50 \%$ short-term clinical success.

\section{Introduction}

Esophagorespiratory fistulas (ERFs) can be congenital or acquired, either in the context of prolonged mechanical ventilation, or mediastinal (esophageal or bronchopulmonary) tumor after surgery of chemoradiation. They are associated with poor quality of life, chronic respiratory symptoms, severe bronchopulmonary infections, and up to $27 \%$ short-term mortality[1]. Surgical management relies on soft tissue interposition or closure of the fistulous tract, with $83 \%$ efficacy, but up to $6 \%$ perioperative mortality [2,3]. Endoscopic therapy using esophageal fully covered self expandable metal stents (FCSEMS) aime at covering the esophageal defect, alone or combined with tracheal stents, only yields a $46 \%$ efficacy [1]. Indeed, stents neither completely seal the fistula, nor promote its healing. Other endoscopic techniques, such as occlusion (by clips or glue), have not shown better results [4].

A minimally invasive alternative using an Amplatzer cardiac or vascular plug septal occluder (AGA Medical, Plymouth, Minnesota, United States), intended for percutaneous vascular or septal defect closure or in cardiology, has been successfully used in endoscopy for ERF closure in humans [5,6]. The Amplatzer consists of two to three biocompatible self-expanding discs made of a nitinol mesh connected together by a thinner 


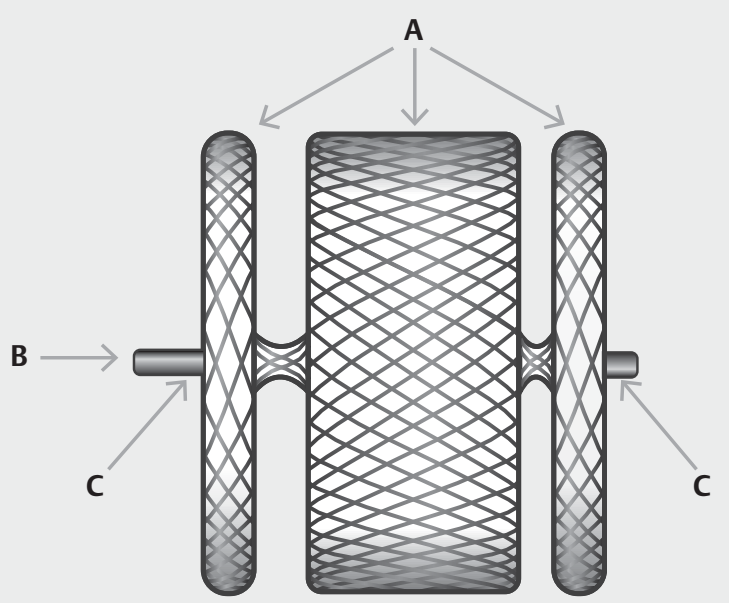

Amplatzer ${ }^{\mathrm{TM}}$ Vascular Plug II

A. Nitinol Mesh, B. Screw attachment, C. Marker bands

A

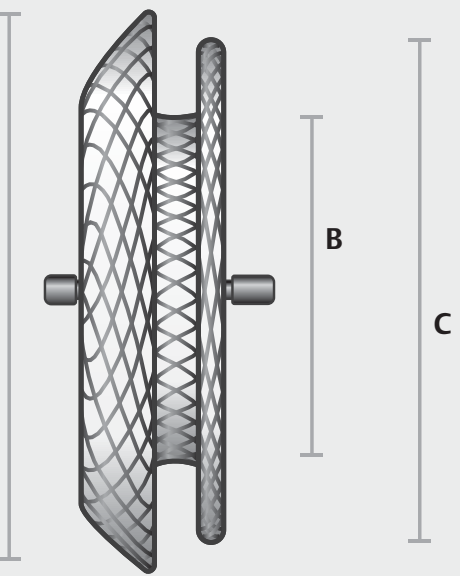

Amplatzer ${ }^{\mathrm{TM}}$ Septal Occluder

A. Left atrial disc, B. Device waist, C. Right atrial disc

- Fig. 1 Two types of Amplatzer occluders used in the series.

waist, ensuring the stability of the device ( $\triangleright$ Fig. 1 ). We describe a case series of six patients with ERF treated with endoscopically placed Amplatzer occluders.

\section{Patients and methods}

\section{Patients}

Between June 2019 and September 2020, six patients had endoscopic closure attempts for chronic acquired ERF using an Amplatzer occluder at our center. All patients were selected after a multidisciplinary board discussion involving anesthesiologists, gastroenterologists, a pulmonologist, and gastrointestinal surgeons. The patients' written informed consent was obtained after explaining the modalities, benefits, and risks of this procedure.

\section{Endoscopic procedures}

The endoscopic procedures were performed using a gastroscope (GIF-1TH190; Olympus, Tokyo, Japan) and a bronchoscope (BFQ 180, Olympus, Tokyo, Japan), with patients under general anesthesia with orotracheal intubation. Insufflation used air instead of $\mathrm{CO} 2$, considering the esophagorespiratory fistula. The ERF was cannulated using the cap-fitted gastroscope (12.4 mm, Model D-201-1104, Olympus, Tokyo, Japan) and a straight catheter (Guide Catheter 6 Fr $220 \mathrm{~cm}$, Cook Medical) in which a guidewire (JagWire straight, $450 \mathrm{~cm} 0.035 \mathrm{in}$, Boston Scientific, Natick, Massachusetts, United States) was inserted. A bronchoscope placed in the trachea through the intubation canula allowed precise localization of the fistula and visualization of the guidewire, and facilitated correct positioning of the Amplatzer. The gastroscope was exchanged for a straight 7 Fr catheter (Destination Guiding Sheath, RSC08, Terumo), which enabled positioning of a Vascular Plug II Amplatzer (AGA Medical, Plymouth, Minnesota, United State), or a 9F catheter (Torqvue Delivery System, Abbott, Plymouth, Minnesota, United States), which enabled positioning of a Septal Occluder Amplatzer (Abbott, Plymouth, Minnesota, United States) depending on the size and shape of the ERF, under double endoscopic control. Successively, one disk was released in the trachea and one or two in the esophagus. Successful closure of the ERF was confirmed by injection of contrast medium into the esophagus showing the absence of passage in the tracheobronchial tree under fluoroscopy. The main steps of the procedure are presented in $>$ Fig. 2.

Patients were followed up clinically to ensure that cough resolved and no new episode of pneumonia had occurred. Thoracic computed tomography (CT) with oral contrast ingestion was performed before resuming food 1 to 2 days after the procedure. A double endoscopic control 2 to 4 weeks after the procedure was performed to check the absence of migration of the device.

\section{Results}

Case 1 was an 80-year-old patient followed for several episodes of aspiration pneumonia and chronic cough after a prolonged intensive care admission for cardiac arrest. The patint was diagnosed with an esophago-tracheal fistula on esophagogram. At $19 \mathrm{~cm}$ from the dental arches, an 11-mm-wide esophago-tracheal fistula on the right side of the esophagus was seen at esophagogastroduodenoscopy (EGD). A 14-mm Amplatzer vascular plug was placed under double endoscopic control. The patient was discharged from the hospital the next day and has not had any respiratory symptoms since then. Follow-up endoscopy 4 months later showed the Amplatzer in place with no contrast medium leakage towards the trachea.

Case 2 was a 67-year-old woman who was admitted to the Intensive Care Unit after an Ivor Lewis esophagectomy following neoadjuvant chemoradiotherapy for treatment of a squamous cell carcinoma of the esophagus. The diagnosis of ERF was suspected based on recurrent aspiration with pneumonia. After confirmation of a 14-mm-wide esotracheal fistula $25 \mathrm{~cm}$ 


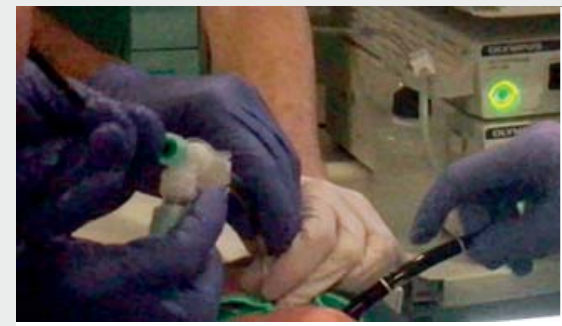

Step 1: Parallel respiratory and digestive endoscopy

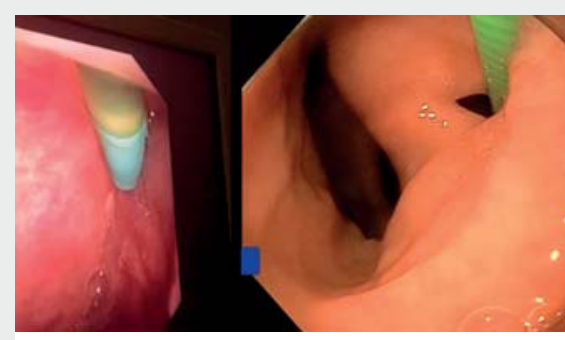

Step 4: Insertion of a straight catheter (left: tracheal side; right: esophageal side)

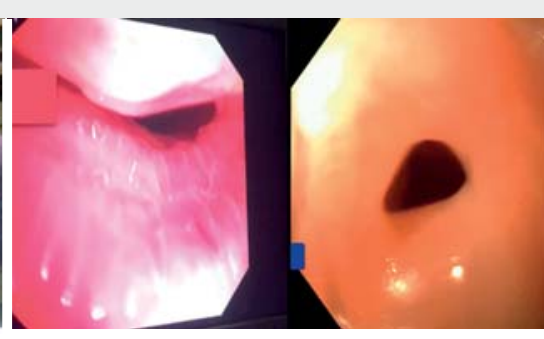

Step 2: Double visualisation of the TEF (left: tracheal side; right: esophageal side)

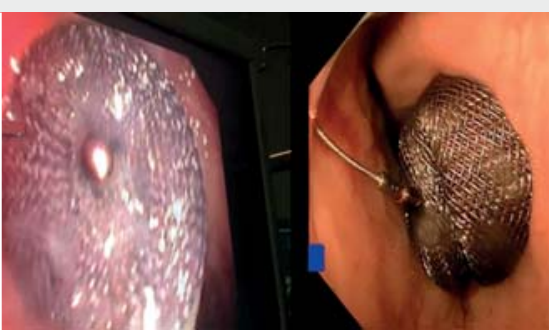

Step 5: Amplatzer release (left: tracheal side; right: esophageal side)

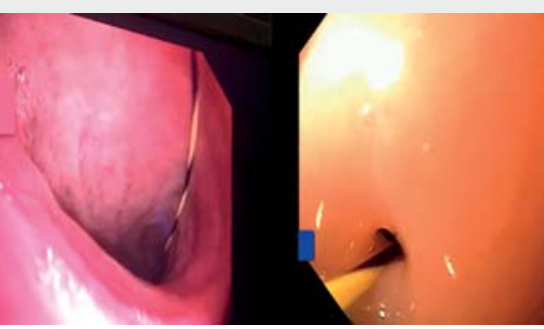

Step 3: Canulation of the TEF left: tracheal side; right: esophageal side)

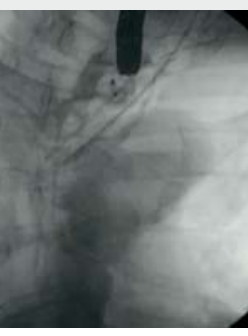

Step 6: Control by opacification

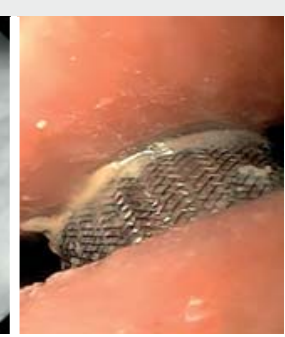

Step 7: Esophagoscopy at 2 weeks

- Fig. 2 Main steps in Amplatzer (vascular plug II) occluder placement in an esophagotracheal fistula.

from the dental arches on EGD, an esophageal FCSEMS was placed on the $12^{\text {th }}$ postoperative day. The patient's respiratory symptoms persisted despite two other endoscopic procedures to replace the stent with larger $(22-\mathrm{mm})$ stents, and we finally placed an 18-mm Amplatzer vascular plug under double endoscopic control 3 months after the surgery. Despite the technical success, the patient died from septic shock of pulmonary origin 3 days after the procedure.

Case 3 was a 60-year-old man who was treated with repeat surgery and chemoradiotherapy for medullary carcinoma of the thyroid and developed a $10-\mathrm{mm}$ ERF, located $21 \mathrm{~cm}$ from the dental arches. There was no evidence of local tumor recurrence. After failure of conventional management using repeat placement of an esophageal FCSEMS, a 14-mm Amplatzer vascular plug was deployed. Initially the procedure was clinically successful, with resolution of respiratory symptoms. However, cough and pneumonia recurred 9 months later and the patient reported new onset of dysphagia. EGD showed an esophageal stenosis located in the cervical esophagus related to a local tumor recurrence. EGD with a nasogastroscope permitted the stenosis to be passed and showed that the Amplatzer was still in place, but only partially occluding an enlarged and tumor-invaded fistula, with contrast leakage in the trachea. Repositioning of the Amplatzer was technically impossible due to the stenosis, and the patient was switched to long-term enteral nutrition.

Case 4 was a 71-year-old man in clinical remission from squamous cell carcinoma of the upper third of the esophagus after intial chemoradiotherapy. He was diagnosed with local and metastatic cancer recurrence 1 year later and an $8-\mathrm{mm}$ ERF located $18 \mathrm{~cm}$ from the dental arches, which caused cough during oral food intake. Placement of a 10-mm Amplatzer vascular plug allowed him to resume a well-tolerated normal diet by mouth beginning on Day 3. However, the patient died 10 days later from massive aspiration pneumonia.

Case 5 was a 56 -year-old patient who was diagnosed with an ERF on a CT performed for workup of a septic shock 12 days after an Ivor Lewis esophagectomy for esophageal adenocarcinoma. EGD showed a $14-\mathrm{mm}$ fistula located $29 \mathrm{~cm}$ from the dental arches and bronchoscopy identified a fistula in the right primary bronchus. The fistula was initially treated with three successive esophageal FCSEMS, without fistula closure. Six months after the surgery, an 18-mm Amplatzer septal occluder was placed and allowed the patient to resume oral food intake with no respiratory symptoms. Follow-up endoscopy 5 months later found the Amplatzer in place with partial reepithelialization on the esophageal side and no contrast leakage towards the respiratory tree.

Case 6 was a 57-year-old man who underwent an Ivor Lewis esophagectomy for an esophageal adenocarcinoma and was diagnosed on the 9th postoperative day with an esophago-tracheal fistula. Initial management consisted of repeated placement of esophageal FCSEMS over a 2-year period. Given the absence of fistula closure, with a remaining $25-\mathrm{mm}$ esophago-tracheal fistula $24 \mathrm{~cm}$ from the dental arches, placement of a 24 $\mathrm{mm}$ Amplatzer septal occluder was attempted. It did not provide a complete occlusion of the fistula, given the presence of an irregular, nodular mucosa on the tracheal side, and was immediately retrieved and replaced with another esophageal stent. The patient remained symptom-free at last follow-up, 4 months after the last endoscopic procedure. Currently, an en- 
- Table 1 Characteristics of the six patients with esophagorespiratory fistulas managed with amplatzer occluders.

\begin{tabular}{|c|c|c|c|c|c|c|c|}
\hline Case & Context of ERF & $\begin{array}{l}\text { Location } \\
\text { (cm from } \\
\text { the DAs) }\end{array}$ & $\begin{array}{l}\text { Size of the } \\
\text { esophageal } \\
\text { fistula }(\mathrm{mm})\end{array}$ & $\begin{array}{l}\text { Amplat- } \\
\text { zer type }\end{array}$ & $\begin{array}{l}\text { Techni- } \\
\text { cal suc- } \\
\text { cess }\end{array}$ & Outcome & $\begin{array}{l}\text { Follow-up } \\
\text { (months) }\end{array}$ \\
\hline 1 & $\begin{array}{l}\text { Prolonged mechani- } \\
\text { cal ventilation }\end{array}$ & 19 & 11 & $\begin{array}{l}\text { Vascular } \\
\text { Plug II, } \\
14 \mathrm{~mm}\end{array}$ & Yes & Clinical success & 15 \\
\hline 2 & $\begin{array}{l}\text { Ivor-Lewis esopha- } \\
\text { gectomy }\end{array}$ & 25 & 14 & $\begin{array}{l}\text { Vascular } \\
\text { Plug II, } \\
18 \mathrm{~mm}\end{array}$ & Yes & $\begin{array}{l}\text { Death } 3 \text { days after the } \\
\text { procedure from pneu- } \\
\text { monia }\end{array}$ & - \\
\hline 3 & $\begin{array}{l}\text { Chemoradiotherapy, } \\
\text { no residual tumor }\end{array}$ & 21 & 10 & $\begin{array}{l}\text { Vascular } \\
\text { Plug II, } \\
14 \mathrm{~mm}\end{array}$ & Yes & $\begin{array}{l}\text { Cancer recurrence, re- } \\
\text { currence of respiratory } \\
\text { symptoms after } 9 \\
\text { months }\end{array}$ & 11 \\
\hline 4 & $\begin{array}{l}\text { Chemoradiotherapy, } \\
\text { residual tumor }\end{array}$ & 18 & 8 & $\begin{array}{l}\text { Vascular } \\
\text { Plug II, } \\
10 \mathrm{~mm}\end{array}$ & Yes & $\begin{array}{l}\text { Death } 8 \text { days after the } \\
\text { procedure from pneu- } \\
\text { monia }\end{array}$ & - \\
\hline 5 & $\begin{array}{l}\text { Ivor-Lewis esopha- } \\
\text { gectomy }\end{array}$ & 29 & 14 & $\begin{array}{l}\text { Septal oc- } \\
\text { cluder, } \\
18 \mathrm{~mm}\end{array}$ & Yes & Clinical success & 5 \\
\hline 6 & $\begin{array}{l}\text { Ivor-Lewis esopha- } \\
\text { gectomy }\end{array}$ & 24 & 20 & $\begin{array}{l}\text { Septal oc- } \\
\text { cluder, } \\
24 \mathrm{~mm}\end{array}$ & No & Technical failure & 4 \\
\hline
\end{tabular}

dotracheal ablation procedure is scheduled to flatten the tracheal mucosa and correctly place an Amplatzer.

Patient characteristics and outcomes data are summarized in $>$ Table 1.

\section{Discussion}

This case series found an $83 \%$ (5/6) technical success rate and a $60 \%(3 / 5)$ short-term clinical success rate with ERF occlusion using endoscopically placed Amplatzers. Because the recommended management of ERF relies on esophageal stents [7], we only included patients with chronic non-malignant ERF refractory to initial management with conventional stents. Thus, we selected cases with well-organized, fibrotic, large fistulas for which clipping, either directly during or after submucosal dissection [8] was not possible. Indeed, the stability of the device requires a regular-shaped and large fistula. Therefore, an Amplatzer is not likely to be an effective treatment for malignant ERF, which is best managed with esophageal, tracheal, or combined stenting; esophageal or tracheal stenoses often increase the stability of the stents [9]. Conversely, the long time between the onset of the ERF and the Amplatzer placement led to the inclusion of an extremely frail patient population, explaining the $33 \%$ (2/6) mortality rate in our series.

The use of Amplatzer occluders, initially designed for cardial septal defect occlusion, in the treatment of non-malignant refractory ERF has been reported in 10 case reports ( 11 patients) since 2006 [5, 6, 10-17]. In four of 11 cases, the ERF occurred after esophagectomy, and in four of 11 patients after pro- longed mechanical ventilation. Clinical success was obtained in $45 \%$ of the cases $(5 / 11)$, with heterogeneous follow-up duration, ranging from 1 month to 1 year. The mortality was high in these 11 extremely frail and malnourished patients, reaching $40 \%(4 / 11)$. In our case series, the mortality rate was $33 \%$, illustrating the severity of the comorbid conditions of the patients, possibly accounting for the limited efficacy of the Amplatzer occluders.

Although Amplatzer occluders can improve the quality of life of a proportion of patients with refractory non-malignant ERF, the device suffers several limitations. First, although long-term follow-up for cardiovascular indications shows an excellent safety profile and endothelial regrowth [18], we only observed moderate epithelial growth on the esophageal side, and never on the tracheal side. This indicates that tracheal obstruction due to granulation tissue will not be an issue, but suggests that the device is only suspensive, and that ERF might recur in case of Amplatzer migration. Second, the size of the intratracheal flap, particularly with the vascular plug-type Amplatzer (for smaller-diameter fistulas), might result in airway obstruction.

Erosion of the respiratory mucosa by the Amplatzer occluder might also constitute a limitation of the use of this device, particularly in the bronchi, considering their limited diameter, because a case of fatal hemoptysis after closure of a gastrobronchial fistula was reported recently [19]. Use of novel occluders specifically designed for the endoscopic treatment of refractory ERF has been reported in a recent animal study [20]. Finally, the outcomes of the patients in case studies 3 and 4 suggest 
that the stability and the efficacy of the Amplatzer occluder can be compromised in cases of active malignancy: therefore, the use of these devices is probably advisable in patients with nonmalignant ERF.

\section{Conclusions}

Endoscopic occlusion of chronic, refractory, non-malignant ERF is feasible, with clinical success in half of such patients. Amplatzer occluders should be considered as a rescue therapy in selected cases that can facilitate avoidance of highly morbid surgical management.

\section{Competing interests}

The authors declare that they have no conflict of interest.

\section{References}

[1] Debourdeau A, Gonzalez J-M, Dutau H et al. Endoscopic treatment of nonmalignant tracheoesophageal and bronchoesophageal fistula: results and prognostic factors for its success. Surg Endosc 2019; 33: 549-556

[2] Muniappan A, Wain JC, Wright CD et al. Surgical Treatment of nonmalignant tracheoesophageal fistula: a thirty-five year experience. Ann Thorac Surg 2013; 95: 1141-1146

[3] Shen KR, Allen MS, Cassivi SD et al. Surgical Management of Acquired Nonmalignant Tracheoesophageal and Bronchoesophageal Fistulae. Ann Thorac Surg 2010; 90: 914-919

[4] Chauhan SS, Long JD. Management of tracheoesophageal fistulas in adults. Curr Treat Options Gastroenterol 2004; 7: 31-40

[5] Repici A, Presbitero P, Carlino A et al. First human case of esophagustracheal fistula closure by using a cardiac septal occluder (with video). Gastrointest Endosc 2010; 71: 867-869

[6] Traina M, Amata M, De Monte L et al. Chronic tracheoesophageal fistula successfully treated using Amplatzer septal occluder. Endoscopy 2018; 50: 1236-1237
[7] Spaander M, Baron T, Siersema P et al. Esophageal stenting for benign and malignant disease: European Society of Gastrointestinal Endoscopy (ESGE) Clinical Guideline. Endoscopy 2016; 48: 939-948

[8] Bertrand G, Jacques J, Rivory J et al. Deep endoscopic submucosal dissection of a refractory tracheoesophageal fistula using clip-andline traction: a successful closure. Endoscopy 2017; 49: 1278-1278

[9] Herth FJF, Peter S, Baty F et al. Combined airway and oesophageal stenting in malignant airway-oesophageal fistulas: a prospective study. Eur Respir J 2010; 36: 1370-1374

[10] Coppola F, Boccuzzi G, Rossi G et al. Cardiac septal umbrella for closure of a tracheoesophageal fistula. Endoscopy 2010; 42: E318-E319

[11] Lee $H$, Jung E, Park $M$ et al. Closure of a gastrotracheal fistula using a cardiac septal occluder device. Endoscopy 2011; 43: E53-E54

[12] Ersoz H, Nazli C. A new method of tracheoesophageal fistula treatment: Using an atrial septal defect occluder device for closure - The first Turkish experience. Gen Thorac Cardiovasc Surg 2018; 66: 679683

[13] Miller PE, Arias S, Lee $\mathrm{H}$ et al. Complications associated with the use of the amplatzer device for the management of tracheoesophageal fistula. Ann Am Thorac Soc 2014; 11: 1507-9

[14] Rabenstein T, Boosfeld C, Henrich R et al. First use of ventricular septal defect occlusion device for endoscopic closure of an esophagorespiratory fistula using bronchoscopy and esophagoscopy. Chest 2006; 130: 906-909

[15] Green DA, Moskowitz WB, Shepherd RW. Closure of a broncho-toneoesophageal fistula using an Amplatzer septal occluder device. Ann Thorac Surg 2010; 89: 2010-2012

[16] Cohen-Atsmoni S, Tamir A, Avni Y et al. Endoscopic occlusion of tracheoesophageal fistula in ventilated patients using an Amplatzer septal occluder. Indian J Otolaryngol Head Neck Surg Off Publ Assoc Otolaryngol India 2015; 67: 196-199

[17] Jiang P, Liu J, Yu D et al. Closure of nonmalignant tracheoesophageal fistula using an atrial septal defect occluder: case report and review of the literature. Cardiovasc Intervent Radiol 2015; 38: 1635-1639

[18] Knepp MD, Rocchini AP, Lloyd TR et al. Long-term follow up of secundum atrial septal defect closure with the amplatzer septal occluder. Congenit Heart Dis 2010; 5: 32-37

[19] Buitrago DH, Pinto D, Berkowitz S] et al. Fatal hemoptysis after closure of gastrobronchial fistula using an Amplatzer vascular device. Ann Thorac Surg 2018; 105: e71-e73

[20] Sang H, Peng L, Zhang G. Tracheoesophageal fistula closed by a new gastrointestinal occluder device. Endoscopy 2020: 1234-6702 